\title{
Evaluating bank readiness for CRM implementation
}

\author{
Tahmineh Torabi Rad* and Farajullah Rahnavard
}

\begin{tabular}{l} 
Department Of Management, Qazvin \\
\hline A R T I C L E I N F O \\
\hline Article history: \\
Received October 15, 2011 \\
Accepted 10 March 2012 \\
Available online \\
13 March 2012 \\
\hline Keywords: \\
customer relationship \\
management (CRM) \\
Evaluation of readiness \\
intellectual \\
Social and technological \\
dimensions \\
\hline
\end{tabular}
\begin{abstract}
A B S T R A C T
These days, we see unexpected changes in customers' behaviors in financial and service institutions, especially in banks. There are different reasons for having such changes but the recent advances of technology could be one of the main reasons. Today banks are obliged to link their existence with customers, recognize their demands and needs in present competitive environment and take necessary actions to increase their productivity. The main objective of the present research is to identify bank readiness for establishing customer relationship management. Findings of the present study show that the readiness degree of bank is well above moderate with respect to intellectual dimension and is below moderate with respect to social and technological dimensions.
\end{abstract}

(C) 2012 Growing Science Ltd. All rights reserved.

\section{Introduction}

During the past two decades, transition from industrial economy and fading away of geographical borders of businesses has increased competition among business enterprises. As a result, we could expect customers to consider competitive advantages of organizational activities. Organizations also have realized that retention of existing customers is less expensive than attracting new ones and the best way to keep them is to obtain meet their satisfaction. In addition, research shows that customer satisfaction can lead to obtain a credible trade name, which increases profitability (Peppard, 2000; Ijaz, 2005). Interest in customer relationship management began to grow in 1990s (Ngai, 2005). In recent few years, this term has attracted a great attention in marketing IT etc. (Foss \& Stone, 2001; Gray \& Byun, 2001). In today economy, CRM has been turned into a superior priority for firms seeking competitive advantage (Anshari et al., 2009). While serving customers was of low priority for organizations in the past, it is in the centre of all their activities and revises marketing and sales strategies (Gebert et al., 2003).

\footnotetext{
* Corresponding author.

E-mail addresses: nhamidi1344@gmail.com (T. Torabi Rad)

(c) 2012 Growing Science Ltd. All rights reserved. 
CRM, in addition to its general meaning also points to a software-hardware system where it needs significant amount of investment for its establishment. On the other hand, failure rate of CRM projects is so high (Kellen, 2002). Unfortunately, in addition to spending a great amount of money in order to design and implement CRM systems in organizations, more than $75 \%$ of these projects dealt with failure (Turban et al., 2002). For instance, a study by CSO Forum (2002) showed that 69.3\% of CRM projects failed to achieve their aims (Greenberg, 2004). In this respect, much research was done to find out the important reasons for failure of CRM projects and each research study examined some factors depending their research questions and field; for example, over-emphasis on systems and technology, lack of accordance between CRM strategy and organizational structure, organizational culture etc. were among these reasons (Lindgreen, 2004; Ocker \& Mudambi, 2002; Snipes et al., 2005). Therefore, it is important to have a good assessment of CRM implementation for taking any action.

Every organization should evaluate platforms of CRM before employing it and if these platforms are not appropriate, employing CRM is doomed to failure. To evaluate the degree of readiness of organization for acceptance of CRM platforms for employing CRM should be identified and assessed (Gray \& Byun, 2001). In the present study, it is tried to evaluate the degree of readiness of bank for implementation of CRM system through identifying and assessing the measures of implementation of this system in organization.

\section{Literature review}

Organizations often face with problems in understanding CRM. They think that only by implementation of hardware, advantages of CRM can be exploited. However, they can achieve this aim only by undertaking customer-oriented business strategies leading to a customer-oriented organizational culture and implementing an information infrastructure along with and integrated and appropriate technology (Reynolds, 2002). Thus, successful implementation of CRM system is achieved by understanding it correctly and identifying its precise definition (Gray, 2005). The following definitions are some of the definitions proposed for this concept, which are summarized in Table 1.

Table 1

Definition of CRM

Various types of CRM Definitions

Definition of CRM from departmental view point from IT and marketing perspective by employing in one limited department or unit (Oakes, 2005). viewpoint (including all functions of a business e.g. production, R\&D, marketing, IT, finance and human resource (Oakes, 2005; 25. Rosenbleeth, 2002).
Description

1-CRM is a term for describing a set of methodologies, processes software and systems helping institutions and firms in effective and organized management of relationship with their customers (Burnett, 2001).

2-CRM is integrating IT with business processes in order to meet customer needs (Parvatiyar \& Sheth, 2002).

3- CRM is the strategic process of selecting profitable customers and defining the infraction between these customers and firm with the aim of optimizing present and future value of customers for the firm (Persson, 2004).

1-CRM is an comprehensive strategy of business and marketing which integrates technology processes and all business activities (Feinberg \& Romano , 2003).

2-Establishment of relationship with all valuable customers via effective use of customer account information (Gray, 2005; Kotler, 2003).

3-CRM is an comprehensive and multi-facet phenomenon including strategic aspects, customer-oriented processes and organizational changes through projects and also performance appraisal (Kirkby \& Nelson, 2002). 


\subsection{Status of CRM in bank system}

CRM can be considered as a strategy for obtaining more insights about needs and trading behaviors of customers for establishing more frequent and stronger relationships with them. In CRM technique, many theologies can be defined and employed; but it is completely incorrect to have only a technological picture in CRM. Thus in order to understand CRM in a better way, it should be considered as a process being used for gathering various information on customers ,sales department, efficacy of marketing activities, rapid responding to customers and also market desires (Gray, 2005).

Financial institutions and banks offer their services in direct relationship with customers, thus in today competitive market, they are obliged to gather information on behaviors and customers' reactions in relation to different strategies adopted by competitors. Indeed CRM consists of all processes and technologies an organization employs in order to identify, select, encourage, expand, maintain and serve customers (SuKim \&Young, 2010). In relation to CRM, various models have been proposed among them 3 ones are more famous. Key specifications of them are reflected in Table 2.

\section{Table 2}

Models for customer relationship

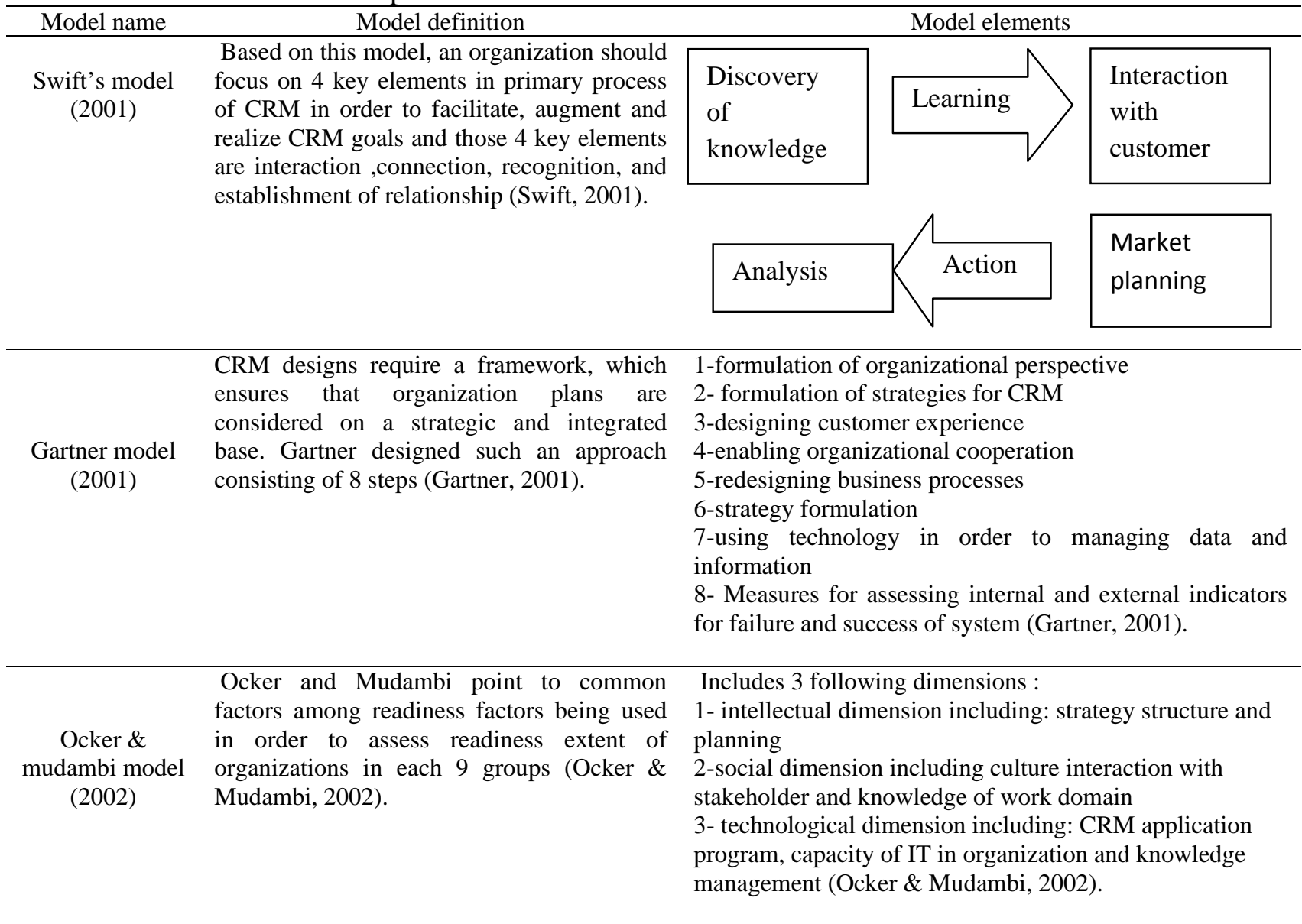

\section{Research model}

There are various models for assessing the readiness degree of organization for establishment of CRM system (Cunningham, 2002; Gartner, 2001; Swift, 2001) but Ocker and Mudambi designed a model consisting of 3 dimensions of intellectual, social and technological ones which is more 
comprehensive than other models (Foss, B., \& Stone, 2001; Hamp \& Swatman, 2002) and is chosen as research model in the present study.

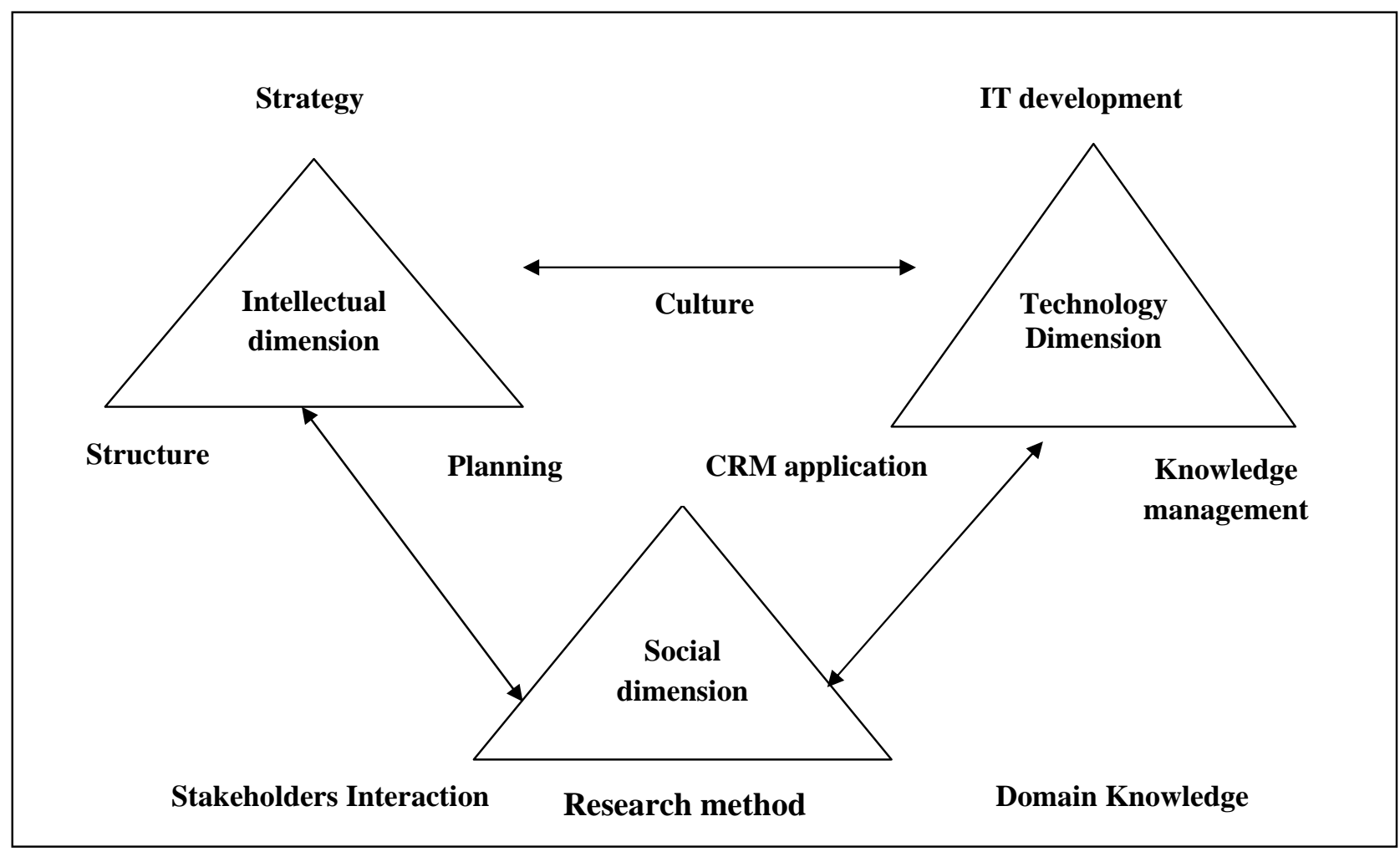

Fig. 1. Ocker \& Mudambi model (research model)

The present research is a descriptive survey one from methodological viewpoint and seeks to obtain opinions of two levels of managers and experts of bank with different branches in Iran. Their common characteristics includes working in bank and being familiar with managerial innovations for improving relationship with customers, about the extent of organizational readiness for establishment of CRM system . In addition, the present research is an applied one respecting to its objective because the results from it can be used in establishment of CRM system in the mentioned organization.

In the present research, Morgan table was used for determining sample size and for population size of 1100, the sample size was determined as 285 persons according to it and among those, 252 persons answered questions of the questionnaire. In the present research, using elements of Ocker- Mudambi model and considering measures for each dimension a questionnaire was formulated with 36 fivechoice questions. In designing the questionnaire, 5-pointLlikert scale was used and the responders were requested to indicate their agreement degree with items (very low, low, moderate, high, very high). In the present study in order to evaluate reliability of questionnaire, questions were developed based on theoretical bases, similar research and consultation with honored professors and in pilot phase ambiguity of questionnaire was eliminated using feedbacks and the main questionnaire was prepared after required modifications and distributed to selected sample. In order to assess validity of questionnaire, Cronbach alpha was used and coefficients for intellectual, social and technological dimensions were respectively 0,89, 0,86 and 0,86 which indicate acceptable validity of questionnaire.

On the other hand in order to assess reliability of each of evaluative measures, Cronbach coefficients were determined as the following table: 
Table 3

Reliability of measures

\begin{tabular}{llll}
\hline \multicolumn{1}{c}{ Question } & \multicolumn{1}{c}{ Cronbach } & Question & Cronbach \\
\hline $1,2,3,4,5,6,7,8$ & 0.8829 & $9,10,11,12,13$ & 0.8620 \\
$14,15,16$ & 0.7813 & $17,18,19,20,21$ & 0.8347 \\
$22,23,24$ & 0.7596 & $25,26,27$ & 0.9594 \\
$28,29,30$ & 0.8309 & $31,32,33$ & 0.9162 \\
$34,35,36$ & 0.9346 & & \\
\hline
\end{tabular}

In order to analyze data, student t-test, to examine the normality of variables, Kolmogorov-Smirnov test and for ranking measures Friedman fest were used.

\subsection{Research questions}

Given the research model research questions consist of:

1- What is the readiness degree of bank for implementation of CRM with respect to intellectual dimension?

2- What is the readiness degree of bank for implementation of CRM with respect to social dimension?

3- What is the readiness degree of bank for implementation of CRM with respect to technological dimension?

\section{Research findings}

Given the finding of the present research, the readiness degree of bank for implementation of CRM with respect to different dimensions of research model is as Fig. 2.

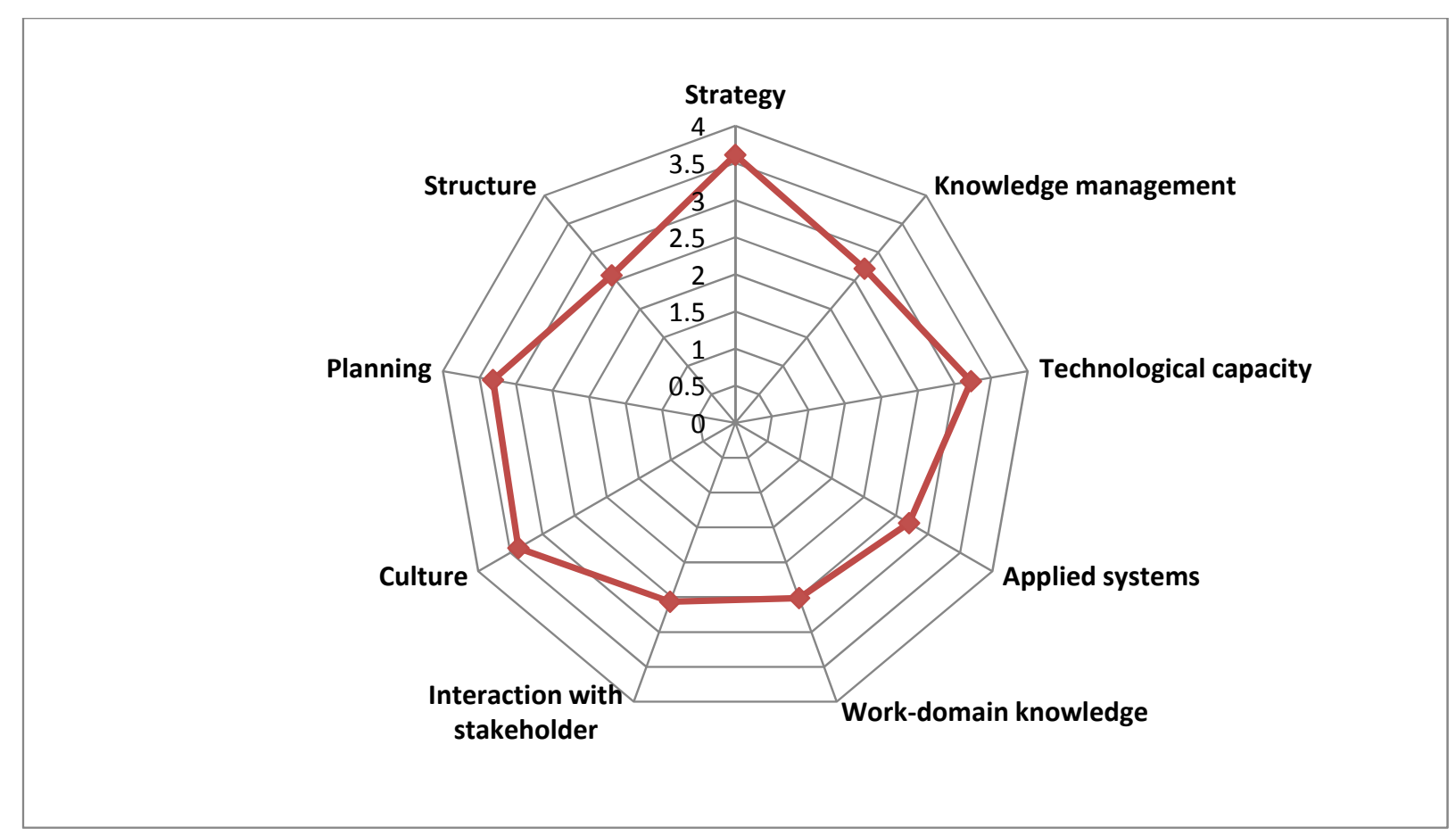

Fig. 2. Spider web model of readiness degree of bank for establishment of CRM 
As is seen in spider web diagram, except for 4 aspects, all other aspects of CRM model are below moderate level on the basis of 5-point Likert scale. This fact suggests that the factors preventing establishment of CRM in bank are at considerable level and some measures should be taken in order to address them.

\subsection{Test for first question}

In order to answer question 1 (what is the readiness degree of bank for establishment of CRM with respect to intellectual dimension) the following statistical hypotheses were proposed, one-sample ttest was used for data analysis and the results from it are summarized in Table 4.

*Readiness degree of bank With respect to intellectual dimension is below or equal to the medium level $H_{0}: \mu \leq 3$

* Readiness degree of bank with respect to intellectual dimension is above the moderate level $H_{0}: \mu>3$

\section{Table 4}

Results for one-sample t-test with respect to intellectual dimension

\begin{tabular}{|c|c|c|c|c|c|c|c|}
\hline \multirow{3}{*}{$\begin{array}{l}\text { intellectual } \\
\text { dimension } \\
\text { elements }\end{array}$} & \multicolumn{7}{|c|}{ Test Value $=3$} \\
\hline & \multirow[t]{2}{*}{ Mean } & \multirow[t]{2}{*}{$\mathrm{t}$} & \multirow[t]{2}{*}{ df } & \multirow[t]{2}{*}{ Sig. (2-taild) } & \multirow[t]{2}{*}{ Mean difference } & \multicolumn{2}{|c|}{$\begin{array}{c}\text { 95\% Confidence Interval } \\
\text { of the Difference }\end{array}$} \\
\hline & & & & & & Upper & Lower \\
\hline Strategy & 3,608 & 12,755 & 251 & 0,000 & 0,6086 & 0,7025 & 0,5146 \\
\hline Structure & 2,592 & $-6,187$ & 251 & 0,000 & $-0,4079$ & $-0,2780$ & $-0,5377$ \\
\hline Planning & 3,314 & 5,143 & 251 & 0,000 & 0,3148 & 0,4354 & 0,1943 \\
\hline $\begin{array}{l}\text { Intellectual } \\
\text { dimension }\end{array}$ & 3,171 & 3,683 & 251 & 0,000 & 0,1718 & 0,2637 & 0,0799 \\
\hline
\end{tabular}

As is seen in the table the mean value for intellectual dimension is 3,1718 and given the significance level, H0 is rejected. Thus bank has the required readiness with respect to intellectual dimension. In more precise way, bank has the required readiness in 2 aspects of strategy and planning given having above-moderate means with respect to these 2 aspects, but it requires enhancement in structure aspect. Besides this intellectual dimension measures were compared using Friedman test for ranking and the results for importance order are as follows:

\begin{tabular}{ccc}
\hline Measures & Rank means & Ranks \\
\hline Strategy & 2,41 & $1^{\text {st }}$ rank \\
Planning & 2,13 & $2^{\text {nd }}$ rank \\
structure & 1,45 & $3^{\text {rd }}$ rank \\
\hline
\end{tabular}

\subsection{Test for second question}

In order to answer the second question

(What is readiness degree of bank for implementation of CRM with respect to social dimension) the following statistical hypotheses were proposed and one-sample t-test was used for data analysis which the results obtained from it are summarized in table5. 
* Readiness degree of bank dimension is below or equal to the moderate level with respect to social dimension $H_{0}: \mu \leq 3$

* Readiness degree of bank is higher than moderate level with respect to social dimension. $H_{0}: \mu>3$

Table 5

Results for one-sample t-test with respect to social dimension

\begin{tabular}{ccccccccc}
\hline & \multicolumn{9}{c}{ Test Value $=3$} \\
\cline { 2 - 8 } Social dimension elements & Mean & $\mathrm{t}$ & $\mathrm{df}$ & $\begin{array}{c}\text { Sig. } \\
\text { (2-taild) }\end{array}$ & $\begin{array}{c}\text { Mean } \\
\text { Difference }\end{array}$ & $\begin{array}{c}\text { 95\% Confidence Interval } \\
\text { of the Difference }\end{array}$ \\
\cline { 2 - 9 } & & & & & & Upper & Lower \\
\hline Culture & 3.3746 & 6.704 & 251 & 0.000 & 0.3746 & 0.4846 & 0.2646 \\
\hline Interaction with stakeholders & 2.5661 & -6.789 & 251 & 0.000 & -0.4339 & -0.3080 & -0.5597 \\
\hline Work-domain knowledge & 2.5132 & -6.754 & 251 & 0.000 & -0.4868 & -0.3448 & -0.6287 \\
\hline Social dimension & 2.8180 & -3.467 & 251 & 0.000 & -0.1820 & -0.0786 & -0.2854 \\
\hline
\end{tabular}

Mean value for social dimension is 2.8180 and because it is less than the hypothesized mean $(\mu<3)$ thus bank is not ready for implementation of CRM with respect to this dimension. Speaking in more precise way, bank has the required readiness in culture aspect given its above-moderate mean in this respect, but it requires enhancement in 2 other aspects i.e. interaction with stakeholders and work domain knowledge. Three measures of social dimension are compared using Friedman test for ranking and their importance order is as follows:

\begin{tabular}{ccc}
\hline Measures & Rank means & Ranks \\
\hline culture & 2,53 & $1^{\text {st }}$ rank \\
Interaction with stakeholders & 1,75 & $2^{\text {nd }}$ rank \\
Work-domain knowledge & 1,72 & $3^{\text {rd }}$ rank \\
\hline
\end{tabular}

\subsection{Test of third question}

In order to answer the third question (what is readiness degree of bank for implementation of CRM with respect to technological dimension) the following statistical hypotheses were proposed and onesample t-test was used for data analysis and the obtained results are reflected in Table 6.

* Readiness degree of bank With respect to technological dimension is below or equal to moderatelevel $H_{0}: \mu \leq 3$

* Readiness degree of bank With respect to technological dimension is higher than moderate level $\left.H_{0}: \mu\right\rangle 3$

Table 6

Results of one-sample t-test for technological dimension

\begin{tabular}{|c|c|c|c|c|c|c|c|}
\hline \multirow{3}{*}{$\begin{array}{c}\text { Technology } \\
\text { dimension elements }\end{array}$} & \multicolumn{7}{|c|}{ Test Value $=3$} \\
\hline & \multirow[t]{2}{*}{ Mean } & \multirow[t]{2}{*}{$\mathrm{t}$} & \multirow[t]{2}{*}{$\mathrm{df}$} & \multirow[t]{2}{*}{ Sig. (2-taild) } & \multirow[t]{2}{*}{$\begin{array}{c}\text { Mean } \\
\text { Difference }\end{array}$} & \multicolumn{2}{|c|}{$\begin{array}{c}\text { 95\% Confidence Interval } \\
\text { of the Difference }\end{array}$} \\
\hline & & & & & & Upper & Lower \\
\hline Application & 2.7037 & -4.177 & 251 & 0.000 & -0.2963 & -0.1566 & -0.4360 \\
\hline IT capacity & 3.2249 & 3.554 & 251 & 0.000 & 0.2249 & 0.3495 & 0.1002 \\
\hline $\begin{array}{l}\text { Knowledge } \\
\text { management }\end{array}$ & 2.7103 & -3.942 & 251 & 0.000 & -0.2897 & -0.1449 & -0.4344 \\
\hline Technology dimension & 2.8796 & -2.068 & 251 & 0.000 & -0.1204 & -0.0057 & -0.2350 \\
\hline
\end{tabular}


As reflected in Table 6. the mean value for technological dimension is 2.8796 and since it is less than hypothesized mean $(\mu<3)$ thus Bank is not ready enough to implement CRM with respect to this dimension and speaking in more precise way, A bank, given having a mean above moderate level in IT capacity aspect, has the required readiness with this respect but it needs to enhance 2 aspects of application and knowledge management. 3 measures from technological dimension were compared using Friedman test for ranking and their importance order is as follows:

\begin{tabular}{ccc}
\hline Measures & Rank means & Ranks \\
\hline Knowledge management & 2.36 & $1^{\text {st }}$ rank \\
\hline applications & 1.92 & $2^{\text {nd }}$ rank \\
\hline IT capacity & 1.72 & $3^{\text {rd }}$ rank \\
\hline
\end{tabular}

\section{Conclusions and recommendations}

Examining various dimensions of CRM in bank showed that though the required characteristics have been realized to some degrees but in general readiness of bank for realization of CRM is at low levels. Thus it is necessary to formulate and implement appropriate plans in order to change the existing situation and achieve complete establishment of CRM.

Findings of the present study show that the readiness degree of Bank in order to implement CRM with respect to intellectual social and technological dimensions is at moderate level with a slight difference that intellectual dimension is a little above and 2 other dimensions are a little below moderate level. Thus considering the elements of each research variables which show weak means, some recommendations can be provided as follows:

a) Findings of the present research show that the degree of bank readiness on intellectual dimension is above moderate-level. According to elements of this dimension, the flowing recommendations can be provided.

1) moving toward flat structure , 2)improving relationships 3)improving processes 4)establishing appropriate rewarding system 5)obtaining trust of customers at a higher degree 6) satisfying customers at a higher degree 7) identifying and meeting customer needs 8)increasing commitment of bank leadership 9) planning at task unit level 10)planning at IT unit level

b) Findings of the present research show that degree of bank readiness on social dimension is below moderate level. According to elements of this dimension the following recommendations can be offered : (1) enhancing culture of information sharing (2) enhancing education level in the organization (3) upgrading degree of employees trust (4) enhancing common belief among employees (5) changing attitude towards technological change (6) raising the degree of recognition of and awareness of stakeholder dynamics (8) upgrading technological understanding of stakeholders (9) deepening knowledge within work units (10) expanding knowledge among work units (11) increasing willingness to share knowledge among common units .

c) Findings of the present research show that the degree of readiness of bank with respect to technological dimension is below moderate level. According to the elements of this dimension the following recommendations can be provided : 1)implementing the system in the organization step-bystep 2)reducing complexity of CRM applied systems 3)reducing customization of CRM applied systems 4)enhancing adequacy of project management specialty 5)forming a balanced expert team 6)benefiting from experiences obtained from starting similar plans 7) enhancing the level of prevalent view towards customer 8) providing appropriate knowledge base in the organization 9)securing appropriate network infrastructure. 
By the way, given the fact that readiness of bank for implementation of CRM is at a low level, it is recommended that other researchers take measures in order to identify factors inhibiting establishment of CRM in this organization so that they can help to start up this system.

\section{References}

Anshari, M., Al-Mudimigha, A., \& Aksoy, M. (2009). CRM initiatives of Banking sector in Saudi Arabia, 17(1), 32-39.

Burnett, K. (2001). The Handbook of Key Customer Relationship Management :The Definitive Guide to Winning, Managing and Developing key Account business. Prentice Hall : New Jersey, 101106.

Cunningham, J. (2002). Customer Relationship Management. Wiley Company Oxford, United Kingdom, 5-11

Feinberg, J., \& Romano, C., (2003), Electronic customer relationship management revising the general principles of usability and resistance - an integrative implementation framework. Business Process Management Journal, 9(5), 340-359.

Foss, B., \& Stone, M. (2001). Successful Customer Relationship Marketing: New Thinking, New Strategies, and New Tools for Getting Closer to Your Customers. Kogan Page, and London.

Gartner, (2001). Framework for customer relationship management. Marketing Research, 11(2), 156163.

Gebert, H., Geib, M., Kolbe, L., \& Brenner, W. (2003). Knowledge-enabled customer relationship management: integrating customer relationship management and knowledge management concepts. Journal of Knowledge Management, 7(5), 107-123.

Gray, P., \& Byun, J. (2001). Claremont Graduate School Center for research on information technology and organization, University of California, Irvine.

Gray, P. (2005). Manager's Guide to Making Decision about Information Systems. New York: Wiley, PP 96-116

Gray, P., \& Byun, J. (2001). Customer Relationship Management, University of California , Available at : $\underline{w w w . c r i t o . u c i . e d u}$

Greenberg, P. (2004). CRM at the speed of light: Essential customer strategies for the 21st century. third edition, McGraw Hill.

Hamp, J., \& Swatman, P. (2002). Customer Relationship Management, Case studies of five Swedish, Luella University technologies.

Ijaz, D. (2005). How Banks Manage CRM Ab2b perspective, master's thesis, university of technology, 1-40.

Kirkby, J. \& Nelson, S. (2002). Key Issues for Customer Relationship Management Strategy.

Kotler, P. (2003). Marketing Management. New Jersey, Prentice Hall, 52.

Lindgreen, A. (2004). The design, implementation and monitoring of a CRM programme: a case study. Marketing Intelligence \& Planning, 22( 2), 160 - 186.

Ngai, E. (2005). Customer relationship management research (1992-2002) An academic literature review and classification. Journal of Marketing Intelligence and Planning, 23(6), 582-605

Oakes, G. (2005). What does a good Customer Relationship Management strategy look like?, www.grahamoakes.co.uk

Ocker, J., \& Mudambi, S. (2002). Assessing the Readiness of Firms for CRM: A Literature Review and Research Model. Proceedings of the 36 Th Hawaii International Conference on System Sciences.

Parvatiyar, A., \& Sheth, J. N (2002). Customer Relationship Management: Emerging Practice Process and Discipline. Journal of Economic and Social Research. 3(2) 2001, 1-34.

Peppard, J. (2000). Customer Relationship Management (CRM) in Financial Services. European Management Journal, 18(3), 312-327.

Persson, P. (2004). Customer Relationship Management: How a CRM system can be used in the sales process. Master of thesis, Luia University of technology. 
Ramaseshan, B., Bejou, D., Jain, S.C., Mason, C., \& Pancras, J. (2006), Issues and Perspectives in Global Customer Relationship Management. Journal of Service Research, 9(2), 195-207.

Reynolds, J. (2002). A Practiocal Guide to CRM: Building More Profitable Customer Relationships. CMP books, pp 1-67

Rosenbleeth, M., \& et al. (2002). Capturing Value through Customer Strategy, Boz Alen \& Hamilton INC, Internet.

Snipes, R.L., Oswald, S.L., LaTourc, M., \& Armenakis, A.A. (2005). The effects of specific job satisfaction facets on customer perceptions of service quality: an employee-level analysis, Journal of Business Research, 58(10), 1330-1339.

SuKim, H., \& Young, G. (2010). Chan-work park Integration of firms resource and capability to implement enterprise CRM a case study of a retail bank in Korea-decision support systems, 313322.

Swift, R. (2001), Accelerating Customer Relationship Using CRM and Relationship Technologies. prentice hall: New Jersey.

Turban, E., \& Mclean, E., \& Wetherbe, J., (2002). Information Technology for Management: Making Connections for Strategic Advantage. New York.

Kellen, V. (2002). Complexity, Fragmentation, Uncertainty and Emergence in CRM, http://www.kellen.net/crmcomp.htm 